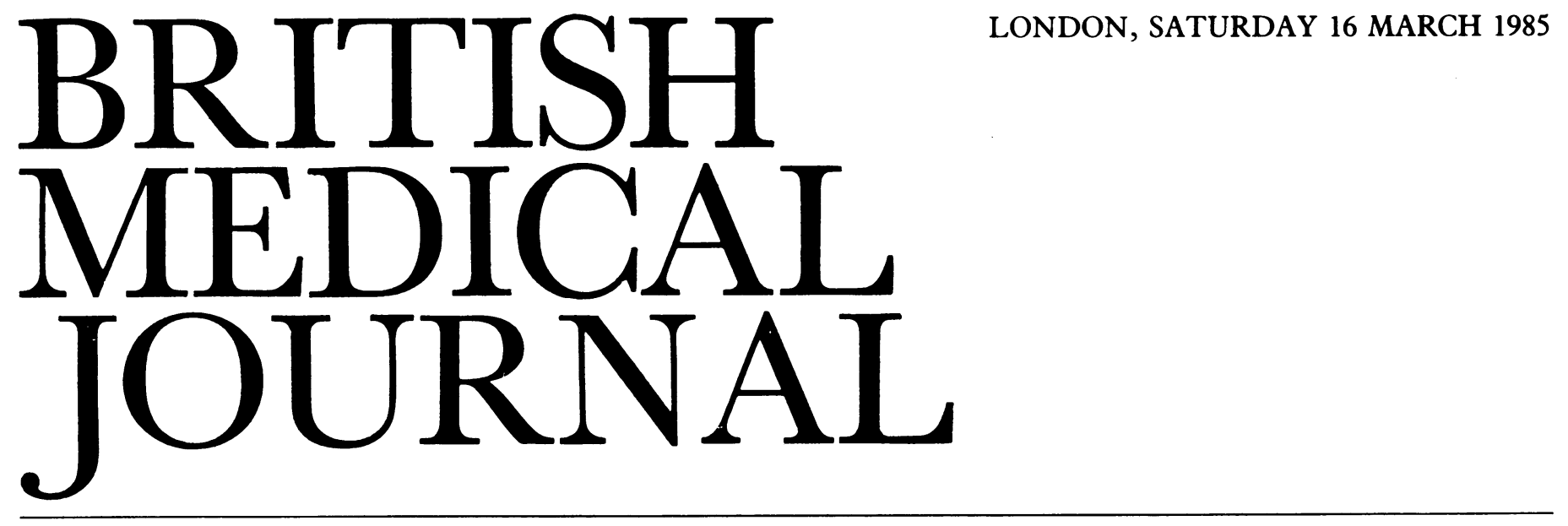

\title{
Alternatives to the digitalis glycosides for heart failure
}

The digitalis glycosides are effective when heart failure is accompanied by fast atrial fibrillation. Their long term value in patients in sinus rhythm is more controversial. A positive inotropic effect may be shown acutely, ${ }^{1.5}$ but this does not seem to be translated into an effective increase in cardiac output in patients with longstanding heart failure ${ }^{67}$ Furthermore, the effect is small compared with those of stimulation by catecholamines and of exercise. No beneficial effect can be shown in patients with cor pulmonale ${ }^{8}$ or cardiogenic shock, ${ }^{9}$ and most patients in sinus rhythm with congestive heart failure due to primary myocardial disease may have their maintenance treatment with digoxin withdrawn without deterioration in their clinical condition. ${ }^{1011}$

This limited value of digitalis as an inotropic agent is combined with a high incidence of adverse effects. Not surprisingly, therefore, investigators have been looking for a potent orally active inotropic agent suitable for use in patients with congestive heart failure. This search has concentrated on two classes of drugs: the $\beta$ adrenergic agonists and the non-sympathomimetic, non-glycoside agents, the bipyridine derivatives. Oraily active phosphodiesterase inhibitors have attracted less interest.

$\beta$ agonists produce short term haemodynamic improvement in patients with congestive heart failure, but few have been shown to be of value in its long term management. Moreover, when the peripheral vascular resistance is increased any beneficial effects brought about by increased cardiac output are reduced.

Single doses of prenalterol have proved effective in patients with heart failure, ${ }^{12}$ but no data have been published on longer term oral treatment-though sustained clinical response has been reported for up to six days after starting the drug. ${ }^{13}$ Pirbuterol differs from most $\beta$ agonists in possessing vasodilator properties in addition to its inotropic action. The drug improves left ventricular function in the short term in a way comparable with that seen with dobutamine, but long term experience has been variable. Some workers have reported improved ventricular function and exercise tolerance sustained for several weeks after starting treatment, ${ }^{14}$ is while others have been unable to show any long term beneficial effects ${ }^{16}$ or have found an attenuation of the clinical responses after one month's treatment accompanied by a reduction in $\beta$ receptor density. ${ }^{17}$ Any judgment on the place of pirbuterol in the long term management of chronic cardiac failure must therefore await the results of further controlled clinical trials.
The $\beta_{2}$ agonist salbutamol given by mouth also improves left ventricular function in patients with severe left ventricular failure, ${ }^{18}$ but presumably this relates more to $\beta_{2}$ mediated peripheral arteriolar dilatation than to the drug's weak $\beta_{1}$ mediated inotropic effects. This compound has a good record of safety in patients with obstructive airways disease, but its efficacy and adverse effects await evaluation in patients with chronic congestive heart failure.

Two orally active forms of dopamine have been investigated in man: the antiparkinsonian drug levodopa, and a potent analogue of dopamine, ibopamine. Treatment with levodopa produces acute inotropic effects in patients with severe heart failure. ${ }^{19}$ Ibopamine causes prolonged shortening of systolic time intervals in healthy volunteers and clinical improvement with increased diuresis in patients with congestive heart failure over a seven day period. ${ }^{20}$

Butopamine is an oral $\beta$ agonist which is structurally related to dobutamine. Though inotropic activity has been shown in normal people, an unacceptable incidence of arrhythmias in patients has limited further development. One other interesting approach is to use a cardioselective $\beta_{1}$ partial agonist such as xamoterol (Corwin). When sympathetic tone is low or normal (for example, at rest or during mild exercise) xamoterol acts as a $\beta_{1}$ agonist producing a modest positive inotropic effect. When sympathetic tone is high the drug tends to act as a $\beta$ adrenoceptor antagonist. This property might be of doubtful value in patients with severe heart failure and high sympathetic tone, but continuing studies have suggested that the drug may be of value in mild to moderate heart failure, ${ }^{202}$ especially when accompanied by angina pectoris. ${ }^{21}$

Probably the most promising orally active inotropic agents and the ones most likely to replace the cardiac glycosides are the dipyridine derivatives amrinone and milrinone. Amrinone, which causes a dose related increase in cardiac contractile force, is the agent which has been most extensively investigated. Its inotropic activity is not decreased by pre-

We apologise to readers for the late arrival of their journals. This is being caused by industrial action at the printers.

Readers are reminded that the $B M \mathcal{F}$ 's current classified job advertisements are also available on Prestel. 
treatment with propranolol or reserpine and there is no evidence that the drug alters cyclic adenosine monophosphate, phosphodiesterase, or $\mathrm{Na}^{+} \mathrm{K}^{+}$adenosine triphosphatase activity. In patients with congestive heart failure the haemodynamic effects of amrinone are characterised by an increase in cardiac output, substantial reductions in left ventricular filling pressure, and reduced systemic vascular resistance. Both blood pressure and heart rate remain unaltered. These observations suggest that the drug possesses both inotropic and vasodilator properties. Amrinone improves ventricular function in patients with severe chronic cardiac failure, ${ }^{22}{ }^{23}$ and myocardial oxygen requirements are not increased..$^{24}$ Unfortunately, the incidence of adverse effects of treatment with amrinone is high, the drug causing asymptomatic thrombocytopenia, gastrointestinal effects - nausea, vomiting, and abdominal pain-abnormal liver function values (including clinical jaundice), diabetes insipidus, myositis, polyserositis, and pulmonary infiltration. ${ }^{25}$

Early experience with amrinone was encouraging in terms of its inotropic activity, but the high incidence of adverse effects will clearly limit the drug's long term usefulness. Milrinone, a derivative of amrinone and almost 20 times as potent as an inotropic agent on a milligram per kilogram basis, seems to be its natural successor. The drug appears to be well tolerated; thrombocytopenia has not been reported in animals, normal volunteers, and patients with congestive heart failure. In 20 patients with severe congestive heart failure intravenous milrinone reduced left ventricular end diastolic pressure, pulmonary wedge pressure, and systemic vascular resistance and increased the cardiac index. Oral treatment in 19 of these patients produced sustained symptomatic improvement for up to 11 months, and in 10 patients the persistent inotropic effect was confirmed with radionuclide ventriculography. ${ }^{26}$ Similar findings have been obtained in 11 patients with severe congestive heart failure over a four week period..$^{27}$

Aminophylline, a phosphodiesterase inhibitor, increases cardiac contractile force and is often used in treating left ventricular failure, but surprisingly no studies have been made of orally active theophyllines in the long term management of heart failure.

Congestive heart failure remains a common final manifestation of ischaemic, valvular, and myocardial disease. Potent diuretics frequently fail to produce adequate symptomatic relief, while excessive diuresis may worsen symptoms resulting from low cardiac output. Vasodilating drugs represent an important advance in the treatment of refractory congestive heart failure but often fail to control symptoms in low output states. The cardiac glycosides have weak inotropic effects which are often not translated into long term clinical improvement, so that there is real need for an orally active inotropic agent with a wide therapeutic index. No such agent is available; long term experience with most orally active inotropic drugs has been disappointing. There are several possible reasons for this. ${ }^{28}$ Firstly, all new inotropic drugs tend to be used in patients with severe heart failure, a condition associated with a progressive downhill course. Clearly a form of treatment which is not directed towards preventing myocardial cell loss or altering the basic pathophysiological features of the condition is likely to meet with little success. In some patients myocardial fibrosis and reactive hypertrophy are so considerable that the myocardium cannot be stimulated further. Secondly, many of the problems in heart failure are related to increased peripheral vascular resistance, so not surprisingly the greatest success has been achieved with inotropic agents which possess vaso- dilating activity or when these drugs are used after an optimum vasodilator effect has been achieved. Finally, chronic inotropic treatment may possibly reduce life expectancy either by exhausting myocardial energy supplies so making the heart failure worse or by precipitating malignant ventricular arrhythmias. ${ }^{28}$ This possibility makes the use of $\beta_{1}$ adrenoceptor agonists, which tend to increase myocardial oxygen consumption, a dubious proposition in the long term management of heart failure.

If we assume that stimulation of the depressed myocardium is beneficial in the long term then the bipyridine group of drugs seem most likely to supersede the digitalis glycosides, either alone or in combination with treatment with vasodilators. Amrinone has many advantages, but the incidence of adverse side effects is unacceptably high. Milrinone, an equally effective compound, seems to be better tolerated and may prove to be the drug of choice in the future. Large clinical trials will be needed to show an overall favourable or unfavourable effect on mortality. The challenge remains that of developing a drug which not only produces symptomatic improvement in heart failure but also prolongs life expectancy.

Senior Lecturer and Consultant Physician,

G D JoHNSTON

Department of Therapeutics and Pharmacology,

Queen's University of Belfast,

Belfast BT9 7BL

Smith TW, Haber E. Digitalis. N Engl J Med 1973;259:945-52

Smith TW, Haber E. Digitalis. N Engl f Med 1973;259:1010-5.

3 Smith TW, Haber E. Digitalis. N Engl F Med 1973;259:1063-72.

4 Smith TW, Haber E. Digitalis. N Engl J Med 1973;259:1125-9.

Crawford MH, Karliner JS, O'Rourke RA. Favorable effects of oral maintenance therapy on lef ventricular performance in normal subjects: echocardiographic study. Am $\mathcal{J}$ Cardiol 1976;38: 843-7.

6 Guz A, McHaffie D. The use of digitalis glycosides in sinus rhythm. Clinical Science and Molecula Medicine 1978;55:417-21.

Yankopoulos NA, Kawai C, Frederici EE, Adler LN, Abelman WH. The hemodynamic effects of ouabain upon the diseased left ventricle. Am Heart f 1968;76:466-80.

8 Schüren KP, Hutteman U. Chronic obstructive Lungenenkranken-die hämodinamische Wirkung von Digitalis beim chronischen Cor Polmonale in Rhe und unter Belastung. Klin Wochenschr 1974;52:736-46.

9 Bradley R. Studies in acute heart failure. London: Edward Arnold, 1977

10 Johnston GD, McDevitt DG. Is maintenance digoxin necessary in patients with sinus rhythm? Lancet 1979;i:567-70.

11 Taggart AJ, Johnston GD, McDevitt DG. Digoxin withdrawal after cardiac failure in patients with sinus rhythm. I Cardiovasc Pharmacol 1983;5:229-34.

12 Hutton I, Murray RG, Boyes RN, Rae AP, Hillis WS. Haemodynamic effects of prenalterol in patients with coronary heart disease. Br Heart $\mathcal{f}$ 1980;43:134-7.

13 Waagstein F, Reiz S, Ariniego R, Hjalmarson A. Clinical results with prenalterol in patients with heart failure. Am Heart 7 1981;102:548-54.

14 Awan NA, Needham KE, Evenson MK, Mason DT. Comparison of hemodynamic actions of pirbuterol and dobutamine on cardiac function in severe congestive heart failure. Am $\mathcal{F}$ Cardiol 1981;47:665-9.

15 Pamelia FX, Gheorghiade M, Bishop HL, et al. Effects of oral pirbuterol in patients with severe congestive heart failure. Circulation 1981;64:IV 295

16 Awan NA, Evenson MK, Needham KE, et al. Hemodynamic effects of oral pirbuterol in chronic severe congestive heart failure. Circulation 1981;63:96-101.

17 Colucci WS, Alexander RW, Williams GH. Decreased lymphocyte beta-adrenergic receptor density in patients with heart failure and tolerance to the beta-adrenergic agonist pirbuterol. $N$ Engl f Med 1981;305:185-90.

18 Kerr CR. Hemodynamic effects of oral salbutamol in patients with severe left ventricular failure. Circulation 1979;60:II 41

19 Rajfer SI, Anton AH, Rossen JD, Goldberg LI. Beneficial hemodynamic effects of oral levodopa in heart failure. Relation to the generation of dopamine. N Engl f Med 1984;310:1357-62.

20 Die Cas L, Manca C, Bernardini B, Vasini G, Visioli O. Non invasive evaluation of the effects of oral ibopamine (SB 7565) on cardiac and renal function in patients with congestive heart failure. f Cardiovasc Pharmacol 1982;4:436-40.

20a Detry JMR, Decoster PM, Brausseur LA. Haemodynamic effects of corwin (ICI 118587), a new cardioselective beta adrenoceptor partial agonist. Eur Heart $\mathcal{f}$ 1983;4:584-91.

21 Detry JMR, Decoster PM, Buy JJ, Rousseau MF, Brausseur LA. Antianginal effects of corwin, a new beta adrenoceptor partial agonist. Am $\mathcal{F}$ Cardiol 1984;53:439-43.

22 Benotti JR, Grossman W, Braunwald E, Davolos DD, Alousi AA. Hemodynamic assessment of amrinone. N Engl f Med 1978;299:1373-7.

23 LeJemtel TH, Keung E, Sonnenblick EH, et al. Amrinone: a new non-glycosidic, non-adrenergic cardiotonic agent effective in the treatment of intractable myocardial failure in man. Circulation 1979;59:1098-104.

24 Benotti JR, Grossman W, Braunwald E, Carabello BA. Effects of amrinone on myocardial energy metabolism and hemodynamics in patients with severe congestive heart failure due to coronary artery disease. Circulation 1980;62:28-34.

25 Wilmshurst PT, Webb-Peploe MM. Side effects of amrinone therapy. BrHeart f 1983;49:447-51.

26 Baim DS, McDowell AV, Cherniles J, et al. Evaluation of a new bipyridine inotropic agentmilrinone-in patients with severe congestive heart failure. N Engl F Med 1983;309:748-56.

27 Maskin CS, Sinoway L, Chadwick B, Sonnenblick EH, Le Jemtel TH. Sustained hemodynamic and clinical effects of a new cardiotonic agent, WIN 47203, in patients with severe congestive heart failure. Circulation 1983;67:1065-70.

28 Le Jemtel TH, Sonnenblick EH. Should the failing heart be stimulated? N Engl f Med 1984;310: 384-5. 